Iztok PREZELJ*

\title{
RADIKALIZEM KOT VIR DRUŽBENIH SPREMEMB IN GROŽNJA NACIONALNI VARNOSTI $* * 1$
}

\begin{abstract}
Povzetek. Radikalizem in radikalna politična gibanja so logični in hkrati problematični odziv na družbene spremembe in probleme. Namen članka je prikazati težauno umeščenost radikalizma med povsem legitimne oblike reagiranja na družbeno stvarnost in potencialno ali celo dejansko grožnjo nacionalni varnosti v primeru nasilnega ekstremizma. Avtor preverja in potrjuje tezo, da je politični radikalizem oblika odzivanja na družbene probleme, ki v primeru uresničitve z največjo verjetnostjo pripelje do velikih družbenopolitičnih sprememb, vendar pa se sooča s tveganjem, da postane grožnja nacionalni varnosti v primeru izvajanja ekstremističnih nasilnih dejanj. Avtor ugotavlja, da je radikalizem rezultat kontinuuma med naraščajočo radikalnostjo ciljev in naraščajočo radikalnostjo implementacije ciljev.
\end{abstract}

Ključni pojmi: radikalizem, radikalna politika, nasilni ekstremizem, terorizem, grožnja nacionalni varnosti

\section{Uvod}

Beseda radikalno izhaja iz latinske besede »radix«, ki pomeni korenine. Radikalen pristop pomeni zagovarjanje daljnosežnih in globokih sprememb v političnem sistemu (Robertson, 1993: 405). Beseda se pogosto uporablja $\mathrm{v}$ povezavi $\mathrm{z}$ razsvetljenstvom in francosko ter ameriško revolucijo. Tudi drugi slovarji opredeljujejo radikalnost kot nekaj, kar izhaja iz korenin, nekaj fundamentalnega in drastičnega. V vsebinskem smislu gre za podpiranje globokih političnih ali socialnih reform (Oxford Advanced Learner's Dictionary, 1992: 1032) ali (ekstremnega krila) določene politične stranke, ki se zavzema za omenjene reforme.

Večina družbenopolitičnih sprememb se dogaja na relativno počasen in postopen način. Lahko pa se dogajajo na hiter ali celo prelomen način.

* Dr. Iztok Prezelj, redni profesor, Fakulteta za družbene vede, Univerza v Ljubljani, Slovenija.

** Izvirni znanstveni članek. DOI: 10.51936/tip.58.3.1009-1029

1 Članek je nastal na osnovi projekta Radikalizacija in celoviti protiukrepi v Republiki Sloveniji RadCePro (CRP V5-1735), ki ga je financirala Javna agencija za raziskovalno dejavnost RS iz državnega proračuna. 
Radikalizem ima naravno željo po izvedbi globokih in hitrih reform, ki jih drugače imenujemo tudi transformacija (družbe, resorja, politike, področja ipd.). Tako radikalizem s svojimi idejami diskontinuitete vedno požanje veliko pozornost javnosti, hkrati pa si lahko nakoplje različne izvedbene probleme, med katerimi bi lahko skozi prizmo današnjega časa izpostavili možno kršenje človekovih pravic, ogrožanje drugače mislečih interesnih skupin, ogrožanje obstoječe politike, družbenopolitične ureditve in celo ogrožanje nacionalne varnosti. Ravno pri nacionalni varnosti je treba izpostaviti, da gre v osnovi za bolj »konservativen« koncept, ki si prizadeva za ohranjanje družbene stabilnosti in se prilagaja na dva temeljna načina: prek demokratičnega in legalističnega postopka sprejemanja zakonodaje in strateških usmeritev ter na osnovi sprememb v varnostnem okolju. ${ }^{2} \mathrm{Te}$ spremembe so večinoma postopne in linearne (beri predvidljive), se pa v zadnjih 20 letih pojavlja vedno več nepredvidljivih in nelinearnih sprememb (Prezelj, 2005), pri čemer radikalizacija ni nobena izjema. Trk revolucionarnih ali transformacijskih idej, ki jih poraja radikalizacija, in razmeroma konservativnega koncepta nacionalne varnosti lahko pripelje do raznolikih problemov, ki se lahko razrešujejo na različne načine.

Radikalizmom je v zgodovini uspelo le občasno doseči revolucionarne spremembe. Če revolucijo v družbenih zadevah razumemo kot zelo redko, celovito, drastično in nenadno spremembo (Abercombie et al., 1994: 358; Oxford Advanced learner's Dictionary, 1992: 1085; Robertson, 1993: 419), potem je jasno, da večina radikalnih političnih prizadevanj pravzaprav ne privede do revolucije. Še posebej poučni so dokazi s področja t.i. revolucije v vojaških zadevah (RMA). Na vojaškem področju se je $v$ devetdesetih letih pojavil koncept RMA, ki naj bi predstavljal revolucionarni način odzivanja oboroženih sil na spreminjajoče se varnostno okolje v vedno bolj tehnološki družbi. RMA kot ekstremni vidik vojaške transformacije je odprl dilemo, koliko sprememb v vojaških zadevah je dejansko revolucionarnih in koliko običajnih oziroma postopnih. Številne študije so pokazale, da so se sodobne oborožene sile po koncu hladne vojne predvsem postopno spreminjale, večje revolucionarne spremembe pa so se pojavile le občasno ali pa jih je mogoče opaziti zgolj skozi prizmo številnih kumulativnih manjših sprememb (Scott, 2009: 215; Moran, 2009: 29; Prezelj et al., 2016). Kugler (2006: 296) je še poudaril, da mora vsaka transformacija obsegati smiselno razmerje med kontinuiteto in diskontinuiteto sprememb.

Politični radikalizem je $\mathrm{v}$ tem smislu razpet med lastni potencial velikih

2 Varnost lahko namreč opredelimo kot "stanje, $v$ katerem je zagotovljen uravnotežen fizični, duhovni in duševni ter gmotni obstoj posameznika in družbene skupnosti v razmerju do drugih posameznikov, družbenih skupnosti in narave (Grizold, 1999: 23). Zaradi tega lahko trdimo, da je nacionalna varnost (in v tem smislu tudi mednarodna varnost) bolj konservativni kot transformacijski ali revolucionarni koncept. 
sprememb in veliko škodo, ki jo lahko sočasno povzroči. Prav tako je razpet med lastno pomembno radikalno idejo in bistveno bolj omejene možnosti njene implementacije. V tem članku postavljamo in preverjamo tezo, da je politični radikalizem oblika odzivanja na družbeno stvarnost in probleme, ki v primeru uresničitve z največjo verjetnostjo pripelje do velikih družbenopolitičnih sprememb, vendar pa se sooča s tveganjem, da postane grožnja nacionalni varnosti v primeru izvajanja ekstremističnih nasilnih dejanj. Verjetnost, da radikalni politični ideji uspe, je majhna in večini radikalnih idej ne uspe. V primeru uspeha pa radikalizem postane najpomembnejša pozitivna gonilna sila družbenega razvoja. Tveganja neuresničitve so velika, med njimi tudi ta, da radikalno gibanje postane prvovrstna grožnja nacionalni varnosti glede na prevladujoče družbenopolitične interpretacije.

Članek se najprej osredotoča na pojasnitev radikalizma in radikalne politike skozi prizmo pozitivnega družbenega doprinosa. V drugem delu avtor izpostavi radikalizacijo in nasilni ekstremizem kot grožnji nacionalni varnosti in obstoječi demokratični ureditvi. Posebna pozornost je namenjena tudi vzrokom za radikalizacijo, saj pripomorejo pri razumevanju razpetosti radikalizacije med pozitivni družbeni doprinos in grožnjo nacionalni varnosti. V sklepnem delu sledi verifikacija zgoraj postavljene teze. Članek je zasnovan na uporabi klasične literature o radikalizaciji (npr. Moghaddam, 2009; Ranstorp, 2010; Schmidt, 2013), politološke literature o radikalni politiki (Pughov zbornik iz leta 2009 in pripadajoče uporabljene članke), literature o terorizmu in ekstremizmu (npr. Combs, 1997; Laquer, 2004; Whittaker, 2004, in Crenshaw, 2014) ter politološke literature o liberalizmu (Gamble, 2001; Bell, 2014; Scott, 2012, in Gane, 2015).

\section{Radikalizem in radikalna politika kot pozitivni družbeni sili v smeri sprememb}

Gradnja kitajskega zidu je bila radikalna ideja, ki se je porodila v 7. stoletju pred našim štetjem, zid se je gradil na območjih po etapah in gradnja je trajala več kot dva tisoč let. Kitajske si v času Marca Pola ni bilo mogoče več predstavljati brez tega megalomanskega zidu, katerega obstoj je bil v glavah celotne kitajske družbe nekako normaliziran. Ta primer kaže, da se radikalna politična ideja lahko normalizira pod določenimi pogoji. Podobno se je zgodilo z vsemi političnimi revolucijami (npr. francosko revolucijo, ameriško osamosvojitveno revolucijo, komunistično revolucijo v Rusiji ipd.), pri katerih je izhodiščna povsem radikalna ideja po uspešni implementaciji privedla do njene popolne normalizacije.

Schmidt (2013: 7) v tem smislu opozarja, da je radikalizem v bistvu relativen koncept, ki je odvisen od opazovalca. Vsi ljudje niso locirani v območje normalnega, tradicionalnega in tako nimajo iste referenčne točke za 
razlikovanje med sprejemljivimi in nesprejemljivimi radikalnimi pozicijami. Še več, zgodovina radikalnosti je pokazala, da se je koncept skozi čas radikalno spremenil. Določene politične stranke, ki so se označevale za radikalne v 19. stoletju, in njihove radikalne politične ideje (npr. volilna pravica za vse, neodvisno od spola ali bogastva) so se spremenile v politični »mainstream« Že v 19. stoletju. V tem smislu je treba poudariti, da so bile liberalnost, antiklerikalnost, prodemokratičnost in druge napredne politične pozicije v 19. stoletju razumljene kot radikalne politične ideje. Na primer, liberalizem se je pojavil kot ideologija in gibanje srednjega razreda ter buržoazije, utemeljen pa je bil na ideji osvoboditve od preostankov fevdalnega in monarhičnega nadzora. Ključni pojmi, kot so laissez faire, temeljne človekove pravice in posameznik (Robertson, 1993: 284), so bili sprva dojeti kot ogrožanje obstoječe ureditve. Na tej osnovi je nastala sodobna kapitalistična ureditev, ki temelji na vzpostavitvi ekonomskega sistema, temelječega na zasebni lastnini, in relativno svobodnem trgu brez večjih intervencij države oziroma le z delnim nadzorom države. ${ }^{3}$ Takšni koncepti so bili absolutno radikalni, kasneje pa so s prihodom liberalnih političnih strank na oblast postali sestavni del družbene realnosti in $\mathrm{v}$ tem smislu normalni. Bell (2014: 689) dodatno ugotavlja, da je sodobni liberalizem uspel vključiti tudi veliko tistih, ki se razglašajo za socialiste, konzervativce, socialne demokrate, republikance, zelene, feministe ipd. Poleg tega pa nekateri neoliberalni avtorji ugotavljajo, da je večina neoliberalnih režimov razočarala svoje podpornike, saj jim ni uspelo uresničiti dramatičnih ciljev zmanjšanja vloge sodobne države (Gamble, 2001: 132). Še bolj nazorna je zgodba komunizma, ki se je začel kot radikalna ideologija, temelječa na ukinitvi zasebne lastnine, enakosti med družbenimi razredi in obstoju zgolj ene politične stranke, ki v imenu inteligence predstavlja in vodi delavski razred. Ideologija komunizma se je uresničila ponekod v obliki socialističnih držav, ki so s svojim obstojem normalizirale komunistično ideologijo in po drugi strani ustvarile percepcijo o obstoju radikalne liberalistične in kapitalistične ideologije. Zanimivo je to, da je po propadu socialističnih režimov v teh državah zopet prevladal liberalistično-kapitalistični pristop, ki je ustvaril percepcijo o radikalnem komunizmu in socializmu.

3 Liberalizem je posledica industrijske, ameriške in francoske revolucije, zato ima svojo ekonomsko (svobodni trg) in politično plat (politične svoboščine). V teoriji liberalizma obstajajo različno radikalni pogledi na vlogo države pri ustvarjanju in delovanju trga: od klasičnih liberalnih pogledov (Locke, Smith, de Tockueville in Hayek), ki so vendarle predvidevali določeno omejeno vlogo države, do modernih pogledov (Mill in Hobhouse), ki so zagovarjali bolj radikalni pogled neomejenega in globalnega liberalizma s še manjšo vlogo države, in do libertarnega pogleda, ki razume državo kot nepotrebno zlo. Razvoj liberalizma je v vsakem primeru omejil vlogo oziroma moč države na trgu, vendar pa ji je tudi omogočil pomembno vlogo pri razvoju samega kapitalizma. Rezultat sprege med liberalizmom, kapitalizmom in klasično državo je država blaginje, v kateri so posameznikom omogočene politične in ekonomske pravice, države pa skrbijo za širše sistemske okvire prostora, kjer se te pravice uresničujejo (Bell, 2014; Gane, 2015; Scott, 2012). 
Radikalna politika je torej politika, ki se loteva problema korenito: poskuša ga izkoreniniti oziroma redefinirati način delovanja družbe. To večinoma ne vključuje revolucije, lahko pa seveda jo. Radikalna politika v tem smislu zagotavlja alternativni pogled na svet (Pugh, 2009: 1). Pri radikalni politiki ne gre samo za radikalne cilje, ampak tudi za radikalnost zavzemanja za te cilje (angl. radical commitments). Pogosto zavzemanje ni dovolj močno in se razvodeni. Po drugi strani pa razkritje zavzemanja pomembno odraža željo po doseganju ciljev (Martin, 2009). Gilbert in Litter (2009: 127) npr. radikalnost leve politike razumeta kot zavzemanje za zgodovinske cilje levice (eliminacija neravnotežij v moči med različnimi skupnostmi, razredi in posamezniki) in voljo po njihovem doseganju izza omejitev aktualne konvencionalne politične in kulturne prakse. Tako se radikalizem navezuje tudi na fundamentalnost pri doseganju ciljev in $\mathrm{v}$ tem smislu avtorja razpravljata o razliki med reformističnimi in revolucionarnimi pristopi. Po njuni definiciji imamo $\mathrm{v}$ zgodovini številne primere radikalnih politik in gibanj, kot so feminizem, modernizem, islamizem, neokonzervativizem, fevdalizem, levo in desno usmerjeni radikalizem, neoliberalizem, socializem, antiglobalizem, antikapitalizem, anarhizem, okoljevarstvo in različna zelena gibanja, mirovna oziroma protivojna gibanja, celo določene oblike multikulturalizma itd. Neoliberalizem oziroma neoliberalistični kapitalizem je kakih petdeset let nazaj veljal za radikalni način reševanja problemov, v vmesnem času je porazil socializem in postal splošno sprejeti način reševanja problemov (Pugh, 2009: 2). Prav tako se je zgodilo z zeleno politiko, ki dandanes ni več radikalna, ampak jo je umiril kapitalizem, ki jo je absorbiral in iz nje ustvaril nove možnosti prodaje (npr. hibridna vozila) (Kingsnorth, 2009). Številne obstoječe nevladne organizacije ne zmorejo dovolj radikalnih perspektiv in politik, ker so večinoma odvisne od vladnega financiranja in ne zmorejo mobilizirati dovolj radikalne energije za spremembe (Short, 2009). Zelo pomembno je, da radikalna politika sloni na neki prepričljivi široki zgodbi in teoriji, ki v svoji osnovi seveda temelji na določenih ciljih, zamerah in skorajda utopičnem verjetju v boljšo prihodnost (Hutton, 2009: 213).

Temeljna problema številnih sodobnih radikalnih gibanj in politik sta njihova fragmentiranost in nezmožnost stopiti pod en krovni koncept. Posledično nobena od radikalnih politik ni sposobna zagotoviti velike alternative obstoječemu in prevladujočemu neoliberalizmu, saj se vse fokusirajo le na določene posamične probleme (grand visions of change versus particularistic visions of change). Številna gibanja se niti ne trudijo ustvariti vseobsegajoče naracije glede primernega življenja v prihodnosti, ampak zavestno ponujajo le partikularne rešitve partikularnih problemov. Niti ni veliko poskusov, da bi jih povezali med seboj, tudi protesti so mnogokrat zelo individualizirani. Tipični primer je nedavna globalna gospodarska kriza, ki je bila v bistvu rezultat neoliberalističnega koncepta finančnih 
tveganj. Nobena radikalna alternativa ni bila zmožna prevladati v tej krizi nad neoliberalizmom v smislu vzpostavitve novega sistema družbene organizacije, čeprav je vredno omeniti vzpostavitev globalnega gibanja Occupy, ki je $s$ protesti $v$ več sto mestih po svetu uspelo mobilizirati veliko število ljudi. Gibanje je na osnovi gesla »Mi smo 99\%«protestiralo proti nepravični razdelitvi bogastva v družbi in nesankcioniranju odgovornosti za globalno gospodarsko krizo. Kljub izraženi podpori in simpatiji nekaterih aktualnih in nekdanjih vodij držav ter politikov gibanju vendarle ni uspelo vzpostaviti zadostne osnove $\mathrm{v}$ smeri dejanske vzpostavitve alternativnega družbenega sistema, ki ne bi temeljil na neoliberalizmu. To pomeni, da ta kriza ni bila izkoriščena za univerzalno transformacijo družbe (Pugh, 2009: 5, 8). Tako niti ni presenetljivo, da se čez čas številni nosilci radikalnih idej umaknejo, ker ne dosežejo svojih ciljev.

Literatura izpostavlja radikalnost nekaterih danes že uveljavljenih konceptov, kot je celo multikulturalizem. Po Cohenu (v Pugh, 2009: 9) so postmoderni multikulturalisti privedli liberalno idejo tolerance do ekstrema oziroma ekstremnega relativizma, v katerem je »narobe, če liberalni politiki napadajo/kritizirajo predhodno neprivilegirane skupine (the other), četudi te skupine hkrati zagovarjajo antiliberalne ideje«, kot so seksizem, homofobija in fašizem (seveda $\mathrm{z}$ vidika drugih kultur). $\mathrm{V}$ tem primeru lahko vidimo, kako je lahko prevladujoča ideja liberalizma v primeru doslednega uresničevanja v bistvu grožnja sami sebi in svojemu obstoju.

Tudi Crenshawova (2014) opozarja, da je težko definirati radikalno, saj je percepcija radikalnosti odvisna od posameznika in okolja, torej od okoliščin. Vedenje, ki je v nekem okolju normalno, je v drugem lahko razumljeno kot radikalno. Med drugim tudi zaradi tega številni avtorji ugotavljajo, da je radikalizacija koncept, ki je slabo definiran, kompleksen in celo kontroverzen. $V$ literaturi je izpostavljeno tudi dejstvo, da je radikalizem pogosto povezan z nostalgijo oziroma da ga družba potrebuje, ker gre v bistvu za odzivanje na izgubo. Nostalgija pomaga pri zbiranju energije za vnovično doseganje ciljev (Bonnett, 2009: 179-180).

Iz povedanega bi lahko izpeljali, da je eno pomembnejših vprašanj pri radikalni politiki stopnja radikalnosti. Manj radikalna politika se bo borila proti obstoječi razporeditvi moči v okviru obstoječih institucij, medtem ko se bo bolj radikalna borila tudi proti tem institucijam. V tem smislu McCauley in Moskalenko (2010, citirano v Schmidt, 2013: 7) razlikujeta med aktivizmom in radikalizmom na osnovi legalnosti aktivnosti: aktivizem je pripravljenost na legalno in nenasilno politično akcijo, medtem ko se radikalizem nanaša na pripravljenost na nelegalno in nasilno politično aktivnost (legalni aktivizem versus nelegalni radikalizem). Vendar Schmidt ugotavlja, da se v praksi radikalci niso nujno posluževali nasilnih metod, ter glede na metode radikalizma razlikuje med nasilnim in nedemokratičnim radikalizmom (ki 
uporablja prisilo in cilja na revolucijo) ter nenasilnim in demokratičnim radikalizmom (ki uporablja prepričevanje in cilja na reformo). Schmidt (2013: 14) nadalje v modelu radikalizacije politike dobro opredeli spekter politične aktivnosti od nenasilnih do nasilnih za nedržavne ter tudi državne akterje. Državni akterji lahko zagovarjajo vladavino prava, temelječo na kompromisu, lahko začnejo izvajati zatiralsko politiko pritiska, ki temelji na družbenemu nadzoru, diskriminaciji, nadlegovanju in zlorabi kriznih pooblastil, v končni fazi pa lahko začnejo z izvajanjem različnih oblik nasilja, aretacij, umorov, državnega terorizma ipd. Nedržavna politična gibanja pa tudi podobno lahko najprej igrajo vlogo demokratične opozicije, kar lahko $\mathrm{z}$ radikalizacijo preraste $\mathrm{v}$ nenasilne zunajparlamentarne aktivnosti, kot so protesti, demonstracije, bojkoti, stavke, državljanska nepokorščina, v končni fazi pa lahko pride do uporabe fizičnega nasilja za zoperstavljanje državni moči, kot so na primer uničevanje premoženja, umori, sabotaže, terorizem, oboroženo uporništvo ipd.

\section{Radikalizacija in nasilni ekstremizem kot grožnji nacionalni varnosti v demokratični državi}

Z vidika zagotavljanja družbene stabilnosti in varnosti lahko radikalizem zelo hitro postane ključni vir ogrožanja družbe in države. V tem poglavju želimo pojasniti, kdaj in kako lahko radikalni pristop postane grožnja nacionalni varnosti. Problematična je torej predvsem tranzicija od aktivizma k izvajanju nasilja, kar ponazarjamo na naslednjem grafu in v nadaljevanju besedila.

Kontinuiteta radikalizma je na spodnjem grafu prikazana na relaciji naraščajoče radikalnosti političnih ciljev (abscisa) in radikalnosti implementacije teh ciljev (ordinata). Slika pokaže možno pot političnega gibanja, skupine ali celo posameznika od družbene apatičnosti, pri čemer ni zastavljenih ciljev glede reševanja družbenega problema (točka 1), do največjega radikalizma v obliki terorizma (točka 6 ). Akter lahko zastavi medle politične cilje in uporabi tudi dokaj medlo implementacijo, kar ga vodi v medlo reševanje tega problema (točka 2). Če akter postavi »realne« politične cilje in realne ali normalne metode za njihovo uresničitev, se pomakne na točko 3, kjer lahko govorimo o običajnem ali normalnem reševanju družbenih problemov. Ker niso vsi akterji zadovoljni s takšnim pristopom, se nekateri pomaknejo na točko 4 in postanejo aktivistični, kar temelji na radikalnejših političnih ciljih in tudi radikalnejših metodah za njihovo uresničevanje. Na tej točki se nekateri aktivisti zadržijo (in ostanejo znotraj spektra zakonitih aktivnosti), drugi pa zaradi povečanja radikalnosti ciljev ali/in metod prestopijo mejo zakonitosti delovanja in postanejo nasilni radikalci ali ekstremisti (točka 5). Obstajajo različne vrste in stopnje nasilja, kar pomeni, da nekateri 
ekstremisti lahko hitro postanejo teroristi v primeru izvajanja ekstremnega nasilja za doseganje ekstremnih političnih ciljev (točka 6).

\section{Graf 1: KONTINUUM RADIKALIZMA GLEDE NA RADIKALNOST POLITIČNIH CILJEV IN NJIHOVE IMPLEMENTACIJE}

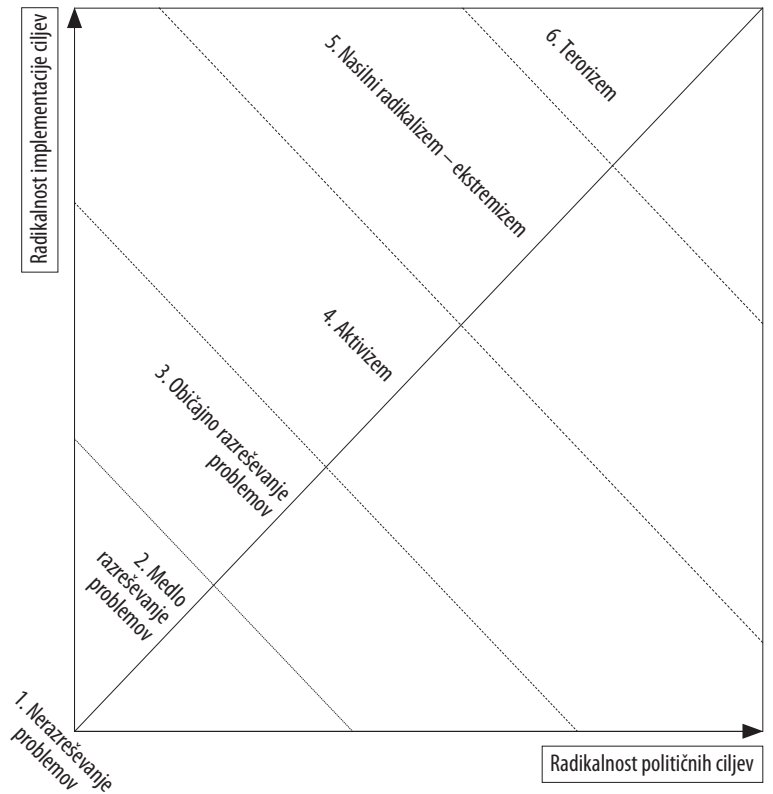

Vir: lastni prikaz.

McCauley in Moskalenko (2008, citirano v Young, Zwenk in Rooze, 2013: 10) razumeta politično radikalizacijo kot povečano pripravo na medskupinski konflikt. V tem smislu radikalizacija pomeni spremembo v prepričanjih, občutkih in vedenju (change in beliefs, feelings and behaviours) v smeri opravičevanja medskupinskega nasilja in zahtev po žrtvovanju pri branjenju svoje skupine. Della Porta in LaFree (2012: 4) sta ugotavljala, da veliko raziskovalcev opredeljuje radikalizacijo kot proces, za katerega je značilna naraščajoča privrženost $\mathrm{k}$ uporabi nasilnih sredstev in strategij v političnih konfliktih. Radikalizacija v tem smislu predstavlja spremembo percepcij proti polarizirajočim in absolutnim definicijam določenih situacij in artikulaciji vedno bolj radikalnih ciljev. V funkcionalnem smislu je politična radikalizacija priprava na medskupinsko nasilje, $v$ deskriptivnem smislu pa radikalizacija pomeni spremembo v prepričanjih, občutkih in vedenju v smeri, ki opravičuje medskupinsko nasilje ter zahteva žrtvovanje za obrambo skupine. 
Schmidt (2013: 18) si pri opredeljevanju radikalizacije pomaga s terminom politične polarizacije in že omenjenega ekstremizma. V tem smislu radikalizacijo opredeli kot individualni ali kolektivni proces, $\mathrm{v}$ katerem se - v situaciji politične polarizacije na eni ali obeh straneh - opustijo običajne prakse dialoga, kompromisa in tolerance med političnimi akterji. Namesto tega se začne uporabljati konfrontacijske taktike, kar vključuje najprej nenasilne pritiske in prisilo, nato pa že različne oblike političnega nasilja (ne še terorizma), aktivnosti nasilnega ekstremizma v obliki terorizma in vojnih zločinov. Ta proces poteka običajno skozi ideološko socializacijo proti radikalnejšim ali bolj ekstremističnim prepričanjem, ki temeljijo na dihotomičnem pogledu na svet. Ta opredelitev poudarja dejstvo, da radikalizacija lahko poteka na obeh straneh polariziranega političnega konflikta.

Zgoraj omenjeni logiki je sledila tudi Evropska komisija, ki je leta 2005 radikalizacijo opredelila kot fenomen, v katerem ljudje privzemajo mnenja, poglede in ideje, ki lahko vodijo v terorizem (Communication from the Commission, the European Parliament and the Council ..., 2005). Ekspertna skupina Evropske komisije za nasilno radikalizacijo je leta 2008 uporabljala delovno definicijo radikalizacije kot socializacije k ekstremizmu, ki se manifestira kot terorizem (Schmidt, 2013: 5). Evropska komisija je radikalizacijo tako vedno obravnavala v okviru celovitega pristopa v boju zoper terorizem, in $s$ tem vzpostavila povezavo med pojmoma radikalizacija in terorizem.

Navedene opredelitve radikalizacije kažejo, da nekateri ekstremizem razumejo kot končno postajo procesa radikalizacije. Radikalizem se pogosto enači z ekstremizmom, vendar po Schmidtu (2013) takšno enačenje ni upravičeno. Oba pojava se lahko opišeta kot idealna tipa distance od zmernih, mainstreamovskih in status quo pogledov, vendar pa je za ekstremiste značilno politično delovanje, ki ne upošteva vladavine prava. Ekstremisti namreč želijo ustvariti homogeno družbo, ki temelji na togi dogmatični ideologiji in zatiranju opozicije ter manjšin. Ekstremistične skupine in stranke imajo torej programe $\mathrm{z}$ naslednjimi elementi: protiustavnost, protidemokratičnost, avtoritarnost, antipluralnost, fanatičnost, netoleranca, zavračanje vladavine prava, uporaba predvsem nasilja in ne toliko prepričevanja, uniformnost in ne diverzifikacija, kolektivni cilji prevladujejo nad individualno svobodo itd. Ekstremistični programi tudi intenzivno uporabljajo ideologijo. Radikalci so torej lahko nasilni ali ne, lahko so demokrati ali ne, medtem ko ekstremisti zagotovo niso demokrati. Za ekstremiste je značilna nefleksibilna rigidnost, ki temelji na poenostavljenih enoznačnih interpretacijah sveta, ki opazovalcu dovoljuje le, da je proti ali pa za (Schmidt, 2013: 9-10). V tem smislu avtor razlikuje med radikalci, ki so odprtega duha (angl. open-minded radicals), in tistimi, ki to niso (angl. closed-mind extremists). Je pa v literaturi zaslediti tudi opredelitve, ki razlikujejo med nasilnimi in nenasilnimi ekstremisti. Slednje Schmidt (2013) označuje kot kontradiktornost - nenasilni ekstremizem je po 
njegovem mnenju oksimoron. Fizično nasilje je v naši družbi seveda prepovedano, razen v samoobrambi. Prav tako ima edinole država monopol nad legitimno uporabo fizičnega nasilja v družbi, ki se mora pri tem držati določb zakonov. Kljub temu se soočamo z nasilnim kriminalom in terorizmom. Zelo povedno je dejstvo, ki ga navaja Moghaddam (2009: 278), da na desetine milijonov muslimanov v zahodnih in nezahodnih družbah trdi, da je nasilje za obrambo islama včasih upravičeno. ${ }^{4}$ Potencial nasilnega ekstremizma v muslimanskih skupnostih torej obstaja.

Intenzivnost ekstremizma je odvisna od stopnje uporabljenega nasilja in pomembnosti cilja (ali je tarča državna infrastruktura, vojska, civilno prebivalstvo, posameznik, otrok). Coleman in Bartoli ekstremiste razdelita $\mathrm{v}$ dve skupini - podrejene, marginalizirane skupine in dominantne skupine (politiki, policisti, pomembne javne osebnosti). Pomembno je poudariti, da ekstremizem ni nujno povezan z uporabo nasilja v fizični obliki, saj lahko ostane na verbalni ravni. Sicer pa ekstremistične marginalizirane skupine ponavadi uporabljajo neposredno nasilje v več stopnjah (na primer bombni samomorilci), dominantne ekstremistične skupine pa večstrukturno, tudi institucionalizirano nasilje (na primer prikrito mučenje in neformalno, brutalno kaznovanje) (Coleman in Bartoli, 2009).

Ekstremni radikalizem se lahko torej v končni fazi sprevrže v terorizem. V tem primeru subjekti svoje radikalne cilje uresničujejo z nasiljem. Za nasilni ekstremizem pa je značilno tudi pozivanje k nasilju ali njegovo spodbujanje (ne da bi nasilje izvajali tudi pozivajoči akterji sami). V tem primeru ekstremistična organizacija še ne postane teroristična ali pa je na meji, da to postane. Southers (2013: 4-6) ugotavlja, da je ima tovrstni ekstremizem šest značilnosti. Prva je nestrpnost in premoč, kar se odraža v netolerantnosti in občutku večvrednosti. Ekstremisti predpostavljajo predvsem moralno večvrednost svoje ideologije, rase, vere in etnične pripadnosti, kar naj bi jim zagotovilo poseben družbeni položaj. Njihovo prevladujoče prepričanje je, da je »svet njihov«, ostali ljudje so lahko hvaležni, da jim je dovoljeno živeti - toda zgolj dotlej, dokler bodo razumeli svoje mesto v družbi. Druga značilnost ekstremizma je stigmatiziranje drugih oziroma drugačnih (t.i. otherism). Predvideva se, da v vsaki družbi obstaja skupina, ki ne razmišlja v okvirih prevladujočega diskurza. Slednje se manifestira v osebnih napadih, ki problematizirajo posameznikove motive, usposobljenost, izkušnje ali znanja. Sociologi ta pojav imenujejo mikroagresija. Zaničevalne etikete za ljudi judovskega, vzhodnjaškega ali neevropskega porekla so običajno uporabljane za preusmerjanje pozornosti od mnenj,

4 Tako pravi 15\% britanskih muslimanov, 16\% francoskih muslimanov, 7\% nemških muslimanov, 10\% indonezijskih muslimanov, 28\% egipčanskih muslimanov, 17\% turških muslimanov in 29\% jordan skih muslimanov (Moghaddam, 2009: 278). 
ki nasprotujejo ekstremistični ideologiji. Tretja značilnost ekstremizma je absolutizem. Ekstremisti namreč verjamejo v manihejski svetovni nazor oziroma v moralni, verski ali filozofski dualizem. Verjamejo v absolutno moralno neoporečnost, pri čemer z vztrajnim ponavljanjem ustvarjajo prepričanje, da so vsi drugače misleči »slabi«. Tovrstno razmišljanje ne dopušča niti prostora niti potrebe po ideološki razpravi (kot tipični primer lahko navedemo Hitlerjev odnos do drugih ideologij). Posledično ekstremisti verjamejo, da so njihova prizadevanja vedno plemenita, medtem ko so drugače misleči vedno nasprotniki. Četrta značilnost je posploševanje brez osnov ali utemeljitev. Ekstremisti posplošeno označujejo in okarakterizirajo ljudi/ družbo, stvari ter dogodke, namesto da bi razpravljali o dejstvih in idejah, ki so v nasprotju s temi posplošitvami. Takšna dejstva najraje ignorirajo ali pa se razpravi o njih izognejo. To vodi do napačnih sklepov, ti pa vodijo do pristranskosti in v nadaljnje sledenje ideološkemu načrtu. Peta značilnost ekstremizma so teorije zarote in scenariji sodnega dne. Ekstremisti pripisujejo apokaliptične posledice neuspehom izvajanja svojega poslanstva. Taki scenariji lahko vključujejo napad na specifično državo, zrušitev vlade s strani tuje sile ali samo zlorabo vlade. Teorije zarote, kot je ideja, da je vlada ZDA sama odgovorna za teroristične napade 11. septembra, krepijo temelj in motivacijo za privrženost ekstremistični ideologiji in služijo za obrambo same skupine. Šesta značilnost ekstremizma pa je obstoj specifične kode za sporazumevanje. Ekstremistične skupine uporabljajo poseben kodni jezik, da s tem očrnijo svoje nasprotnike. Močni izrazi in klišejske besedne zveze jim služijo za hitro spreminjanje ideoloških prepričanj, in to brez potrebe po kritični misli ali razlagi. S krepitvijo predsodkov se veča moralni pogum, s tem pa tudi občutek lastne pravičnosti.

Terorizem pa ni nujna končna postaja radikalizacije. Vsi radikalci niso postali teroristi. Dodatni problem je, da razlikujemo med številnimi vrstami terorizma (levičarski, desničarski, islamistični, etnonacionalistični, samotarski, kiberterorizem itd.), kar pomeni bolj ali manj različne poti radikalizacije. V tem smislu avtorji v literaturi ugotavljajo, da razmerje med radikalizacijo in terorizmom še ni dovolj proučeno. Schmidt $(2013: 17,19)$ ob tem še ugotavlja, da se je $\mathrm{z}$ radikalizacijo zgodilo podobno kot s terorizmom: postal je politiziran termin, ki se ga uporablja $v$ politični igri določanja in pripisovanja krivde. Torej je lahko radikalizacija tudi politični konstrukt, ki ga oblikujejo sistemi nacionalne varnosti.

Na tej točki se zastavlja vprašanje, zakaj se pri radikalnih gibanjih ali skupinah (in ne nazadnje tudi pri posameznikih) pojavlja tovrstna razpetost med pozitivno družbeno silo in grožnjo nacionalni varnosti. Radikalizacija ne more dolgo ostajati samo v ciljih akterjev, ampak se neizogibno pomika proti implementaciji. Če razumemo dejavnike, ki vplivajo na radikalizacijo, lahko tudi bolje razložimo to razpetost. 


\section{Dejavniki radikalizacije družbenih gibanj, skupin in posameznikov}

Za razumevanje radikalizacije in zgoraj izpostavljene razpetosti je zelo pomembno razumeti kontekst oziroma razloge, ki posameznika vodijo in motivirajo v smeri radikalizacije. $\mathrm{V}$ tem poglavju predstavljamo ključne dejavnike radikalizacije. Raziskave kažejo, da ne obstaja posamičen in edinstven razlog za radikalizacijo ter terorizem, temveč kompleksna mešanica internih in eksternih dejavnikov potiska in potega (push in pull) (Schmidt, 2013: 4), pri čemer so dejavniki potiska tisti negativni družbeni, politični, ekonomski in kulturni temeljni vzroki, ki vplivajo na posameznike, da se pridružijo oboroženim radikalnim skupinam, dejavniki potega pa tiste značilnosti radikalnih skupin, ki privlačijo posameznike, da se jim pridružijo (npr. ideologija skupine, občutek bratstva in pripadnosti, sloves in možnost slave itd.). Ključni dejavnik, ki prispeva k izvajanju terorističnega nasilja, lahko po mnenju Evropske komisije najdemo v kombinaciji zaznane ali dejanske nepravičnosti ali izključitve iz družbe v kombinaciji s pritegujočimi silnicami glede sodelovanja $\mathrm{v}$ določeni skupini, ki izvaja aktivnosti v smeri sprememb. Sodelovanje pri nasilnih dejanjih lahko tako postane način vključitve v skupino. Drugi dejavniki izhajajo iz napačne interpretacije besedil ter ideologij ipd. (Commission of the European Communities, 2005: 12-14).

Vzroke za radikalizacijo, ki lahko vodijo v terorizem, je mogoče opazovati in proučevati na treh ravneh (Schmidt, 2013: 4)5:

1. Mikroraven oziroma raven posameznika, kar vključuje probleme z identiteto, neuspelo integracijo, občutke odtujenosti, marginalizacijo, diskriminacijo, relativno deprivacijo, ponižanje (neposredno ali posredno), stigmatizacijo in zavračanje, kar se pogosto kombinira z moralnim ogorčenjem in željo po maščevanju. Ta raven se ukvarja s tem, kako se domnevno ranljivi posamezniki radikalizirajo s pomočjo teroristične propagande ali rekruterjev.

2. Mezoraven oziroma širše radikalno okolje (wider radical milieu), ki povezuje teroriste s širšim okoljem, v katerem lahko dobijo podporo, radikalizirajo nove kadre, dobijo zatočišče. Koncept radikalnega miljeja sta najprej predstavila Waldmann in Malthaner leta 2010, ko sta opozorila, da obstaja pomemben kolektiv ljudi izza same teroristične skupine, ki ga ne smemo spregledati, saj ponuja zatočišče, pomoč, omogoča rekrutacijo novih kadrov, politično in moralno podporo ipd.

3. Makroraven oziroma vloga vlade in družbe doma in v tujini, radikalizacija javnega mnenja in strankarske politike, napeti odnosi med večino in manjšino, še posebej v zvezi s tujimi diasporami, vloga pomanjkanja

\footnotetext{
5 Pregled številnih del kaže, da se avtorji večinoma osredinjajo prav na eno od teh treh ravni.
} 
socialnih in ekonomskih priložnosti v družbi, kar lahko vodi k mobilizaciji in radikalizaciji nevključenih (disconnected). Ta raven se fokusira na aktivnosti oblasti doma in v tujini, odnos družbe do manjšin ipd.

Pomikanje ali nepomikanje določene skupine v kontinuumu radikalizacije je torej v dokajšnji meri odvisno od kompleksne interakcije dejavnikov potiska in potega na zgoraj navedenih ravneh. Povsem mogoče je, da npr. na ravni posameznika obstajajo močni dejavniki potiska, vendar pa jih na makroravni zavre specifična vladna politika.

Schmidt (2013: 4) nadalje ugotavlja, da obstaja določena negotovost $\mathrm{v}$ zvezi s tem, kaj pripada posamezni ravni, še posebej gre za zahtevno razlikovanje med mezo- in makroravnjo, prav tako pa se večina obstoječih raziskav osredotoča na mikroraven, kar hkrati pomeni zanemarjanje druge in tretje ravni. Še več, raziskave se premalo osredinjajo na neproduktivni protiterorizem (counter-productive counter-terrorism), kar je značilno še posebej za tista proučevanja, ki jih financirajo same države. S tem se ustvarja neprimerna osnova za protiradikalizacijske in protiteroristične politike.

V literaturi najdemo številne primere, ki bolj ali manj neposredno tekmujejo za primarnost identificiranih vzrokov. Ne glede na to lahko rečemo, da v literaturi zaznamo naslednje politične dejavnike radikalizacije: represija, pomanjkanje svobode izražanja, odtujenost, stanje v zaporih (pri radikalizaciji v zaporih), vojaška okupacija itd. Zadnja se izkaže kot en od temeljnih dejavnikov v primeru oblikovanja in popolnjevanja ISIS zaradi »okupacije«s strani ameriških vojaških sil (Bondokji, Wilkinson in Aghabi, 2017: 13-15) in tudi v primeru Al Kaide. Percepcija tuje okupacije je tudi sicer glavni motivacijski dejavnik pri separatistični radikalizaciji. Iz tega je, denimo, črpala IMRO (Internal Macedonian Revolutionary Organization) v boju za osvoboditev izpod otomanske oblasti. Zapis pravice do samoodločbe narodov v Ustanovno listino OZN leta 1945 je še dodatno okrepil motivacijo vseh družbenih skupin, ki so se želele osamosvojiti po drugi svetovni vojni z večjo ali manjšo uporabo nasilja. Glavni motiv (dejavnik potega) separatističnih skupin je odcepitev oziroma vzpostavitev nove neodvisne države večinoma na etnični osnovi (Combs, 1997: 40-42) in glavni dejavnik potiska je percepcija represije s strani okupatorske entitete (karkoli že to pomeni). Patriotizem je mehanizem, ki se zelo rad uporablja v procesu tovrstne radikalizacije. IRA in njene naslednice so črpale motiv iz boja zoper okupatorsko silo, vendar so motivacijsko osnovo medetničnih in medverskih razlik zelo uspešno nadgradili s poudarjanjem socialnoekonomskih razlik, ki se pod okupacijo še povečujejo (Whittaker, 2004: 103).

Dokazi glede socio-ekonomskih dejavnikov radikalizacije so zelo protislovni in mešani. Nezaposlenost in korupcija sta bila navajana zelo zgodaj kot ključna dejavnika, vendar ju je novejša literatura izločila. Schmidt (2013: 25) v zvezi s tem ugotavlja, da revščina kot samostojni dejavnik ne vodi v 
terorizem, lahko pa $\mathrm{v}$ to smer vodi nezaposlenost $\mathrm{v}$ kombinaciji z drugimi dejavniki. Na področju islamistične radikalizacije so študije sicer pokazale, da prihajajo tuji borci, torej borci iz Evrope, ki so se po radikalizaciji pridružili terorističnim skupinam v tujini, iz različnih socio-ekonomskih okolij in da jih je bila pred radikalizacijo večina zaposlenih, kar pomeni, da fenomena evropskih tujih borcev ne moremo razložiti z njihovimi socio-ekonomskimi profili; lahko pa imajo ekonomski dejavniki - možnost pridobitve posojila, obljuba dobre službe itd. - pomembno motivacijsko vlogo v afriških, bližnjevzhodnih in centralnoazijskih državah (primeri ISIS in Boko Haram). Nekateri avtorji namesto revščine raje izpostavljajo vlogo »relativne deprivacije«, torej diskrepance med tem, kar posameznik misli, da si zasluži, in tem, kar dejansko ima ter pridobi. Nekateri viri kot vzrok radikalizacije izpostavljajo tudi možnost poroke, ki je odigrala pomembno vlogo v primeru moških in žensk, ki so se pridružili ISIS (Bondokji, Wilkinson in Aghabi, 2017: 14-16). Na primeru nemških in italijanskih levičarskih radikalnih skupin iz prejšnjega stoletja ter na primeru španske ETE se je izkazalo, da veliko radikalcev oziroma teroristov sploh ni prihajalo iz slabih ekonomsko-socialnih razmer. Tako je Whittaker (2004: 143) terorizem ETE označil kot rezultat prospetitete in rasti v Kataloniji in ne slabih ekonomskih razmer.

Literatura izpostavlja tudi številne družbene dejavnike in skupinsko dinamiko. $\mathrm{V}$ tem smislu je pri nekaterih pomembna priložnost za avanturo, ki jo doživijo z radikalizacijo in pomikanjem po zgoraj prikazani daljici. Še posebej mladi v procesu odraščanja iščejo priložnosti, vznemirjenje, adrenalin ipd. Npr. sirijski konflikt je nekaterim ponujal enkratno življenjsko priložnost druženja z brati, bojevanja za pravo stvar in celo možnost postati junak (Bondokji, Wilkinson in Aghabi, 2017: 14-16), prav tako se je željo po avanturi pogosto omenjalo pri številnih primerih levo usmerjene radikalizacije (Whittaker, 2004: 197).

Literatura pogosto omenja vlogo družbenih omrežij, kot so družina in prijatelji. Schmidt (2013: 27) je denimo ugotavljal, da so družbena omrežja ali okolja, ki so radikalna (radikalni milje), in sorodstvene zveze zelo pomembne pri usmerjanju ranljivih posameznikov v smeri terorizma. Takšni radikalni miljeji lahko predstavljajo privlačnost za ranljivega posameznika, ki išče prijateljstvo, novo vlogo, identiteto in status, še posebej, če delujejo dejavniki potiska, kot so diskriminacija, marginalizacija in ponižanje v družini, šoli, soseski in družbi (ibid.). V to smer je še posebej intenzivno raziskoval Sageman. Študije o tujih borcih v ISIS ugotavljajo pomembno vlogo prijateljev, bratov in drugih sorodnikov (ki so jim sledili radikalizirani), svojo vlogo so odigrale celo matere (Bondokji, Wilkinson in Aghabi, 2017: 17-18).

Literatura izpostavlja tudi kulturne dejavnike radikalizacije. V tem smislu sta še posebej pomembni religija in pa vloga narativov. Nekatere študije poudarjajo, da stopnja posameznikovega poznavanja islama ne korelira z 
njegovo nagnjenostjo k radikalizaciji. Ključno vlogo odigra namreč napačna interpretacija verskih naukov v kombinaciji z identifikacijo s proaktivno versko skupino. Verska pripoved oblikuje svetovni nazor, v katerem naj bi posamezniki našli svojo vlogo. Če je to pripoved o žrtvovanju, potem spodbudi kontekstualne frustracije in motivira posameznike k akciji, ki odpravi te probleme, kar v končni fazi lahko vodi tudi k opravičevanju nasilja kot moralnega akta. Pri islamističnem terorizmu v tem smislu veliko vlogo odigrajo fatve, razsodbe verskih voditeljev, ki opravičujejo ali zapovedujejo nasilje (Bondokji, Wilkinson in Aghabi, 2017: 19-22). Tipična motivacijska naracija separatističnih radikalnih skupin (npr. IRA) uporablja koncepte kolonizacije, poniževanja, viktimizacije, marginalizacije, diskriminacije, deprivacije in občutek nečesa izgubljenega $\mathrm{v}$ zgodovini, kar je treba v prihodnosti spet oživeti (Whittaker, 2004: 101-108).

Anarhistične nasilne skupine so hotele popraviti družbene neenakosti z nasiljem, najbolj ekstremistične med njimi pa na osnovi nihilizma odpraviti vse oblike kakršnekoli družbene strukture (Combs, 1007: 48). Npr. nemška RAF je črpala motiv iz nujnosti nasilnega delovanja proti arbitrarnim in nasilno represivnim nemškim oblastem, ki ne spoštujejo niti lastnih zakonov. Glavni sovražniki so bili država Zahodna Nemčija, imperializem, potrošniška družba, Amerika in celo NATO (Whittaker, 2004: 197-207). Za italijanske Rdeče brigade so bili glavni motivi nepravičnosti, uperjene proti delavskemu razredu, občutek izključenosti iz političnega sistema v luči več desetletne vladavine desno usmerjene stranke, imperializem, ki ga predstavlja lastna država, svetovni kapitalizem in desno usmerjene fašistične skupine, ki so aktivno delovale v državi (ibidem, 214-216). Evropske anarhistične radikalne skupine se v zadnjem času rade fokusirajo tudi na vladne migracijske politike in izražanje solidarnosti z migranti (TESAT - EU Situation and Trend Report, 2018: 15).

Radikalne skupine ekstremne desnice se v svoji motivacijski shemi včasih sklicujejo na voljo boga (ki ne more dopuščati moralnega razpadanja družbe ipd.), korupcijo in neodgovorno vedenje vlade, ki ga včasih označijo za terorizem, razne oblike zarote proti patriotom (npr. s strani judov, Američanov, OZN ...), uničujočo globalizacijo, nevarni multikulturalizem in nevarnost migrantov. Zanimivo je, da se motivacijski strukturi levih in desnih radikalnih skupin $\mathrm{v}$ določenih elementih prepletata - sta si podobni (Laquer, 2004: 147-160). Sodobne desne skupine motivacijo črpajo tudi iz zavračanja azilnih politik, obsojanja članstva lastne države v NATO in EU, strahu pred islamizacijo zahodnega sveta, muslimansko dominacijo in uvedbo šeriatskega prava, širjenjem islamskih molilnic v Evropi itd. (TESAT - EU Situation and Trend Report, 2018: 51-52).

Viri med dejavnike vpliva štejejo tudi medije; ti lahko radikalizacijo spodbujajo s prenosom informacij $\mathrm{v}$ imenu terorističnih ali radikalnih skupin 
(npr. glej Prezelj, Kocjančič in Marinšek, 2018; Communication from the Commission, the European Parliament and the Council ..., 2005: 13). V zadnjem času se še posebej izpostavlja uporaba socialnih medijev za spodbujanje radikalizacije. Npr. do leta 2017 so teroristične in radikalne skupine uporabile okrog 150 platform socialnih medijev za propagando in delitev informacij. Poleg tega so uporabljali tudi temni splet (Dark net) za zaupno deljenje datotek, anarhistične skupine so si izražale solidarnost na svojih spletnih straneh in podobno (glej TESAT - EU Situation and Trend Report, 2018: 15, 48).

Ne gre pozabiti na pogosto zanemarjeni dejavnik maščevanja oziroma protiterorističnega terorizma (glej dela Beatrice de Graaf), pa tudi ne na Schmidtovo opozorilo (2013: 37), ki ga izpelje iz del McCauleyja in Moskalenka, da radikalizacija enega družbenega akterja pogosto prispeva $\mathrm{k}$ radikalizaciji druge strani. Drugače povedano, polarizacija v družbi ali med družbami pogosto radikalizira obe strani. To pomeni, da gre pri radikalizaciji za odnose akcije in reakcije, ki jih lahko le redko nadzoruje le ena stran. Avtorji izpeljejo, da obravnava radikalizacije enega akterja zahteva v resnici spremljanje radikalizacije »nas« in »njih«. Konvencionalna literatura s področja terorizma in ekstremizma pa mnogokrat spregleda ravno ta vidik; lahko bi celo rekli, da je stroka mnogokrat slepa glede aktivnosti vlade/države doma in v tujini. V tem smislu Schmidt (2013: 39) izpostavlja tudi dejavnike radikalizacije, kot so zahodni odzivi nanjo ter dejanska in zaznana zahodna dominacija. Vendar pa do podobnih ugotovitev bolj ali manj implicitno prihajajo tudi nekateri drugi avtorji. Npr. Mueller je v svoji študiji petdesetih islamističnih terorističnih zarot proti ZDA po 11. septembru 2001 ugotovil, da je bilo vsem zarotnikom skupno ogorčenje in bes nad ameriškimi in izraelskimi akcijami na Bližnjem vzhodu ter goreča želja po maščevanju ali branjenju v vojni proti Islamu.

Ranstorp (2010: 4) je na podlagi pregleda različnih pristopov skušal razdeliti dejavnike radikalizacije na zunanje in notranje (zunanja in notranja dimenzija). Med notranje dejavnike je uvrstil: očitno pomanjkanje razprave med muslimani glede opravičevanja nasilja, politično polarizacijo in polarizirajočo javno retoriko, stigmatizacijo, krizo identitete, odtujenost od družbe, navzočnost radikalnih imamov, glorifikacijo džihada in mučeništva ter diskriminacijo, stigmatizacijo in kriminalizacijo, ki so jim podvrženi mladi, kar jih dela dojemljive za rekrutiranje. Korteweg in sodelavci (2010: 31-32) so te dejavnike konkretizirali. Pomanjkanje dialoga v muslimanskih skupnostih glede verskih tekstov odraža tudi konflikt idej in interpretacij znotraj islama, kar pomeni, da bi morali alternativnim glasovom islama dati priložnost, da se med seboj soočijo. Politična polarizacija in stigmatizacija muslimanskih skupnosti skozi javni diskurz prispeva k temu, da se mladi muslimani počutijo izločeni iz družbe in začnejo iskati identiteto tudi v nasilnih strujah 
islama, $\mathrm{k}$ čemur pripomore socio-ekonomski zaostanek muslimanskih skupnosti in njihova splošno nizka stopnja integracije v evropsko družbo. Visoka stopnja nezaposlenosti ali pomanjkanje priložnosti krepijo občutke izločenosti iz družbe; ekstremistični islamizem, ki ga pogosto širijo radikalni imami v državah članicah EU, tem ljudem ponudi nov smisel. Pri tem še posebno vlogo igra saudski vahabistični tok denarja, ki podpira radikalne imame ter ortodoksne mošeje, $\mathrm{v}$ katerih se srečata interni in eksterni radikalizacijski proces. Med džihadisti obstaja razprava o glorifikaciji mučeništva in džihada, ki privlači še posebej ranljivo mladino, ki se sooča s stigmatizacijo, diskriminacijo in kriminalizacijo. Mediji v takšnem okolju delujejo kot katalizator - spletne strani in novičarski portali omogočajo kandidatom, da pridejo v stik z »vratarji« (gatekeepers), ki omogočajo povezavo z radikalno organizacijo. Gre za posameznike, ki delujejo v mošejah, humanitarnih organizacijah, na internetu ipd. Kortweg in sodelavci kot primarna območja radikalizacije in rekrutacije, še posebej posameznikov, ki iščejo nov in višji pomen življenja, omenjajo tudi zapore.

Med zunanje dejavnike radikalizacije posameznikov $\mathrm{v}$ muslimanskih državah pa je Ranstorp (2010) uvrstil zahodno zunanjo politiko, zaznano nepravičnost pri muslimanskih skupnostih, še posebej na konfliktnih območjih, kot so Čečenija, Irak, Kašmir, Somalija in palestinska ozemlja, vojaško intervencijo zahodnih držav itd. Pri konkretizaciji dejavnikov Korteweg in sodelavci (2010: 32-33) navajajo, da je za džihadiste pomembna sama pripadnost zahodni civilizaciji, kar predstavlja osnovo za določanje sovražnika. Muslimani v evropskih državah se pogosto identificirajo z muslimani $\mathrm{v}$ muslimanskih državah in jih zato še posebej prizadenejo specifični vidiki zahodne politike, kot so vojaške intervencije z muslimanskimi civilnimi žrtvami, tokovi razvojne pomoči režimom na Bližnjem vzhodu, ki pomagajo ohranjati korumpirane in avtoritarne režime na oblasti, itd.

Kako nam torej dejavniki ali vzroki za radikalizacijo pomagajo pri odgovarjanju na vprašanje, zakaj se pri nekaterih gibanjih, skupinah in posameznikih pojavlja omenjena razpetost med pozitivno družbeno silo in grožnjo nacionalni varnosti? Zgornje klasifikacije raznolikih vzrokov v bistvu pokažejo, da družba vsakega posameznika ali skupino, ki ji posamezniki pripadajo, posrka ali vključi v določene vloge. Posamezniki so v izhodišču večinoma dobro misleča bitja, ki si želijo pridobiti pozitivno družbeno vlogo, vendar pa jih življenjske okoliščine tudi same po sebi postavijo v določene vloge, pri čemer se nekateri odločijo za pot radikalizacije ciljev in udejanjanja le-teh. S tem stopijo na pot radikalizacije. Na tej poti igrajo pomembno vlogo zgoraj navedeni dejavniki, ki skupaj zelo otežijo predvidevanje, kdo, kako in v kakšnem obsegu se bo radikaliziral (stopnja nevarnosti).

Zgoraj navedeni dejavniki radikalizacije ne bodo izginili in radikalizacija bo vedno in povsod obstajala - ne glede na protiukrepe. Protiukrepi lahko 
zmanjšajo dejavnike potiska in potega, pri čemer je treba poudariti, da protiukrepi zagotovo presegajo zmogljivosti in odgovornost institucij za nacionalno varnost, kot so policija, obveščevalne službe in vojska. Posamezniki in skupine se bodo tudi vedno soočali z izzivom po bolj radikalnih ciljih ali vsaj po bolj radikalnem (beri učinkovitem) udejanjanju ciljev, saj bodo tako videti bolj učinkoviti in njihov obstoj bo imel v percepciji relevantnih akterjev še več smisla.

\section{Sklep}

S tem člankom potrjujemo zastavljeno tezo o dvojni naravi radikalizma, ki je razklan med potencialom pozitivnega družbenega doprinosa po eni strani in grožnje varnosti po drugi strani. Radikalizem s svojimi idejami diskontinuitete torej vedno požanje veliko pozornost javnosti, hkrati pa si nakoplje različne izvedbene probleme. Družbe so bolj nagnjene k postopnemu spreminjanju, zato le nekateri radikalizmi uspejo v svoji čisti obliki. Večina radikalizmov tako stopi na vlak postopnega udejanjanja družbenih sprememb. To pomeni, da ostajajo v polju legalnega delovanja. Vendar pa mnogi, ki s tem niso zadovoljni, na tej frustracijski osnovi radikalizirajo svoje cilje in dejanja. Radikalizacija je v tem članku predstavljena kot rezultat kontinuuma med naraščajočo radikalnostjo ciljev in naraščajočo radikalnostjo udejanjanja ciljev. Vendar pa se postavlja vprašanje, ali z radikalizacijo res postanejo bolj učinkoviti ali pa je radikalizacija le zdravilo za njihov prejšnji neuspeh. Nenehna eskalacija radikalnih gibanj v smeri terorizma večinoma tudi ne privede do doseganja ciljev, saj ne nazadnje tudi večina terorističnih skupin ne doseže svojih ciljev.

Redkim radikalnim gibanjem uspe zbrati zadostno podporo javnosti ali s kakim drugim prijemom prevzeti oblast v konkretni družbi. Tedaj začnejo s kognitivno normalizacijo lastne radikalnosti in stigmatizacijo drugih konkurenčnih radikalizmov. Tako se je zgodilo z liberalizmom in komunizmom. Liberalizem še zdaj uspešno parira različnim radikalnim pogledom glede urejanja temeljnih družbenih razmerij. Zanimivo je tudi to, da je liberalističnemu kapitalizmu uspelo vsaj deloma absorbirati nekatere konkurenčne radikalizme in jih $\mathrm{v}$ tem smislu nevtralizirati (npr. liberalistična vključitev zelenih gibanj).

Življenjski cikel radikalizacije se tako prične z nastankom in prvo artikulacijo radikalizma, vrhunec je v potencialnem prevzemu oblasti, s pomočjo katerega se radikalizem normalizira, v primeru izgube oblasti pa obstaja velika verjetnost, da bo prišlo do ponovne kognitivne radikalizacije. Pogosta stalnica radikalnega gibanja je frustracija nad drugimi in seboj.

Politični radikalizem je torej razpet med lastnim potencialom velikih sprememb in škodo, ki jo lahko sočasno povzroči. V primeru radikalizacije 
do točke, ko akterji začnejo z izvajanjem nasilja (ki ni neposredno samoobrambne narave), prestopijo linijo zakonitosti in postanejo grožnja. Pri tem je treba poudariti, da je identificiranje fizičnega nasilja $v$ fizičnem prostoru bistveno enostavnejše od identifikacije in obravnave verbalnega nasilja.

Gibanje po kontinuumu radikalizma pa ni samo v smeri radikalizacije, temveč tudi nazaj v smer deradikalizacije. To je logično, saj večina radikalizmov ne doseže svojih ciljev, pri čemer se nekateri akterji umaknejo, drugi pa še bolj radikalizirajo. Zgornja razprava o dejavnikih, ki vplivajo na radikalizacijo, je pokazala, da je pomikanje ali nepomikanje določene skupine v kontinuumu radikalizacije $\mathrm{v}$ dokajšnji meri odvisno od kompleksne interakcije faktorjev potiska in potega. Ti dejavniki se včasih seštevajo in hitro vodijo $\mathrm{v}$ radikalizacijo, lahko pa se nevtralizirajo in do nadaljnje radikalizacije ne pride. $V$ tem smislu je razpetost družbenih skupin in gibanj ter posameznikov zelo kompleksna in včasih celo paradoksalna. V vsakem primeru je tudi zelo težko predvidljiva, ne samo s strani zunanjih opazovalcev (npr. policija in obveščevalne službe), ampak celo s strani samih opazovanih akterjev. Nepredvidljivost gibanja akterjev v smeri radikalizacije ali nazaj je torej ključna spremenljivka, ki se ji ne moremo izogniti in jo moramo upoštevati pri kakršnikoli obravnavi radikalizacije.

Na koncu se zastavlja še vprašanje, katere vrste radikalizem in ekstremizem (npr. levi, desni, islamistični ipd.) lahko najbolj ogrozi obstoječo družbeno ureditev in nacionalno varnost. Menim, da vse vrste radikalizacije, če se razrastejo brez omejitev, ogrožajo demokratično politično ureditev. Neofašizem bi uporabljal demokracijo kot fasado za uresničevanje lastnih ciljev, radikalni islamizem bi demokracijo ukinil, radikalna levica pa bi ukinila večino nastavkov sodobne države. To pomeni, da brez dodatnih poglobljenih študij ni mogoče reči, katera oblika ekstremizma bolj ogroža nacionalno varnost sodobne demokratične države.

\section{LITERATURA}

Abercombie, Nicholas, Stephen Hill in Bryan Turner (1994): Dictionary of Sociology. London: Penguin Books.

Bell, Duncan (2014): What is Liberalism? Political Theory 42 (6): 682-715.

Bondokji, Neven, Kim Wilkinson in Leen Aghabi (2017): Understanding Radicalization: A Literature Review of Models and Drivers. Hague: Ministry of Foreign Affairs of the Netherlands.

Bonnett, Alastair (2009): Radicalism is Nostalgia. V: Jonathan Pugh (ur.), What is Radical Politics Today?, 179-187, Basingstoke: Palgrave Macmillan.

Combs, Cindy C. (1997): Terrorism in the Twenty-First Century. New Jersey: Prentice Hall.

Crenshaw, Martha (2014): Conslusion. V: Lorenzo Bosi, Chares Demetriou in Stefan Malthaner (ur.), Dynamics of Political Violence, 293-303. USA: Ashgate.

Della Porta, Donatella in Gary Lafree (2012): Process of Radicalization and 
De-Radicalization. International Journal of Conflict and Violence 6 (1): 4-10.

Gamble, Andrew (2001): Neo-Liberalism. Capital \& Class 25 (3): 127-134.

Gane, Nicholas (2015): Trajectories of Liberalism and Neoliberalism. Theory,

Culture \& Society 32 (1): 133-144.

Gilbert, Jeremy in Jo Litter (2009): Beyond Gesture, Beyond Pragmatism. V: Jonathan Pugh (ur.), What is Radical Politics Today?, 127-135, Basingstoke: Palgrave Macmillan.

Grizold, Anton (1999): Obrambni sistem Republike Slovenije. Ljubljana: Visoka policijsko-varnostna šola.

Hutton, Will (2009): Radical Politics after the Crisis. V: Jonathan Pugh (ur.), What is Radical Politics Today?, 213-220. Basingstoke: Palgrave Macmillan.

Kingsnorth, Paul (2009): Victim of Success: Green politics Today. V: Jonathan Pugh (ur.), What is Radical Politics Today?, 36-44. Basingstoke: Palgrave Macmillan.

Korteweg, Rem, Sajjan Gohel, Francois Heisbourg, Magnus Ranstorp in Rob De Wijk (2010): Background Contributing Factors to Terrorism. V: Magnus Ranstorp (ur.), Understanding Violent Radicalization: Terrorist and Jihadist Movements in Europe, 21-49. London: Routledge.

Kugler, Richard (2006): Policy Analysis in National Security Affairs: New Methods for a New Era. Washington, D.C.: National Defense University Press.

Laquer, Walter (2004): No End to War: Terrorism in the $21^{\text {st }}$ Century. London: Continuum.

Martin, James (2009): A Politics of Commitment. V: Jonathan Pugh (ur.), What is Radical Politics Today?, 120-126. Basingstoke: Palgrave Macmillan.

Moghaddam, Fathali M. (2009): De-Radicalization and the Staircase from Terrorism. V: David Canter (ur.), The Faces of Terrorism: Multidisciplinary Perspectives, 277-292. Oxford: John Willey and Sons Ltd.

Moran, Daniel (2009): On Military Revolution. V: Jasper Scott (ur.), Transforming Defense Capabilities; New Approaches to International Security, Boulder: Lynne Rienner Publishers.

Prezelj, Iztok (2005): Nacionalni sistemi kriznega menedžmenta. Ljubljana: Fakulteta za družbene vede.

Prezelj, Iztok, Erik Kopač, Aleš Žiberna, Anja Kolak in Anton Grizold (2015): Evolutionary Reality of the Revolution in Military Affairs: Results of a Comparative Study. Romanian Journal of Political Science 15 (2): 4-34.

Prezelj, Iztok, Klemen Kocjančič in Urša Marinšek (2018): Islamist Radicalisation towards Extreme Violence and Terrorism. Šolsko polje: revija za teorijo in raziskave vzgoje in izobraževanja 29 (5/6): 85-105.

Pugh, Jonathan (2009): What is Radical politics Today? V: Jonathan Pugh (ur.), What is Radical Politics Today?, 1-14. Basingstoke: Palgrave Macmillan.

Ranstorp, Magnus (2010): Introduction. V: Magnus Ranstorp (ur.), Understanding Violent Radicalization: Terrorist and Jihadist Movements in Europe, 1-18. London: Routledge.

Robertson, David (1993): Dictionary of Politics. London: Penguin Books.

Schmidt, Alex P. (2013): Radicalisation, De-Radicalisation, Counter-Radicalisation: 
A Conceptual Discussion and Literature Review, ICCT Research Paper, Hague: International Centre for Counter-Terrorism.

Scott, Alan (2012): Capitalism as Culture and Statecraft: Weber-Simmel-Hirschman. Journal of Classical Sociology 13 (1): 30-46.

Scott, Jasper (2009): Measuring Progress. V: Jasper Scott (ur.), Transforming Defense Capabilities New Approaches for International Security, Boulder: Lynne Rienner Publishers.

Short, Clare (2009): The Forces Shaping Radical Politics Today. V: Jonathan Pugh (ur.), What is Radical Politics Today?, 59-68. Basingstoke: Palgrave Macmillan.

Southers, Erroll (2013): Homegrown Violent Extremism. Oxford: Elsevier Inc.

Yemelinova M., Galina (2007): The Growth of Islamic Radicalism in Eurasia. V: Tahir Abbas (ur.), Islamic Political Radicalism, 83-98. Edinburgh: Edinburgh University Press Ltd.

Young, Holly F., Frederike Zwenk in Magda Rooze (2013): Terrorism and Radicalisation - TerRa: A Review of Literature on Radicalization and What it Means for TERRA, projektno poročilo. Dostopno prek www.terra-net.eu, 20. 5. 2018.

Whittaker, David J. (2004): The Terrorism Reader. New York: Routledge.

\section{VIRI}

Coleman, Peter in Andrea Bartoli (ni datuma): Addressing Extremism. The International Center for Cooperation and Conflict Resolution. Dostopno prek http:// www.libertyunderattack.com/wp-content/uploads/2015/06/AddressingExtremism-ICCCR-ICAR.pdf, 3. 8. 2009.

Commission of the European Communities (2005): Communication from the Commission, the European Parliament and the Council concerning terrorist recruitment: addressing the factors contributing to violent radicalization. Dostopno prek https://eur-lex.europa.eu/legal-content/EN/TXT/PDF/?uri=CE LEX:52005DC0313\&from=EN, 21. 9. 2005.

Oxford Advanced Learner's Dictionary (1992), Oxford: Oxford University Press. TESAT - EU Situation and Trend Report 2018, EUROPOL, dostopno prek: https:// www.europol.europa.eu/activities-services/main-reports/european-union-terrorism-situation-and-trend-report-2018-tesat-2018, 12. 8. 2020. 